\title{
Additional Evidence of Gradual Loss of Germ Cells in the Pathogenesis of Streak Ovaries in Turner's Syndrome
}

\author{
LESTER WEISS \\ From the Department of Pediatrics and the Cytogenetics Laboratory, Henry Ford Hospital Detroit, Michigan, USA
}

The report by Singh and Carr (1966) demonstrating that the gonads of early 45,X embryos appear normal by both gross and microscopic examination has resulted in speculation that some $45, \mathrm{X}$ individuals might have normal sexual development. This report deals with a patient who had a 45,X karyotype, normal sexual development, and regular menstrual periods. No evidence of mosaicism was demonstrated.

\section{Case Report}

The patient (HFH Med. No. 19301 19) was first seen at the Henry Ford Hospital when she was $14 \frac{1}{2}$ years old. She was referred for the evaluation of short stature and mental retardation. The patient was born to a 22-yearold, gravida 1, abortus 0 mother after 8 months' gestation and weighed $1904 \mathrm{~g}$. Her father, at that time, was 27 years old. At birth she was apnoeic and had a poor heart beat but responded quickly to resuscitation and had no additional respiratory distress, jaundice, or cyanosis. Her parents first became concerned about her development at 9 months of age because she was not able to sit. Her subsequent development was slow but her mother could give very few details. The patient walked at approximately 21 months of age and started riding a bicycle at 14 years of age. She was always shorter than her peers. Her height was consistently below the 3 rd centile except for a brief period between the ages of 10 to 12 years when it rose to slightly above the 3rd centile. It was at that time that the patient had her adolescent growth spurt. She had the onset of her menses at 11 years of age and the menstrual periods have been regular since that time. Breast development and other secondary characteristics developed at approximately the same time as the menarche. The family history revealed that there was a normal, younger male sib, no miscarriages, and that the maternal and paternal grandmothers had diabetes mellitus.

Physical examination revealed a very short, hyperactive, retarded child with pinched facies who had

Received 29 December 1970. metallic retainers on her upper teeth (Fig. 1). She had many pigmented naevi; height was $129 \mathrm{~cm}$ which was within the 50th centile for an $8 \frac{1}{2}$-year-old female, and weight was $34.6 \mathrm{~kg}$. Her pulse, blood pressure, respiratory rate, visual acuity, and audiometric testing were all normal. Her head was symmetrical; there was minimal acne vulgaris present and she had malaligned teeth. Her hairline was low but there was no webbing of the neck. Ptosis of the eyelids was not noted. The thyroid was not enlarged. The breast development was that of a post-adolescent female, quite striking in a child of such small stature. The nipples were slightly pigmented. The heart was normal. The fingers were short but the metacarpals did not appear particularl short. Cubitus valgus was present. The axillary haif was sparse. Examination of the abdomen was negative The external genitalia were those of a normal adult female with normal female hair distribution. There were no localizing neurologic defects. Her mental retardation was obvious.

Psychometric testing on several occasions revealed that her IQ ranged between 55 and 60 .

Complete blood count, urinalysis, serum electrolytes, protein bound iodine, blood urea nitrogen, serum calcium, phosphorus, and alkaline phosphatase were all normal. Urinary gonadotropins were positive at 16 mouse units and negative at 96 mouse units. Urinary 17 ketosteroids, 17 hydroxysteroids, and the response to metapyrone were normal. The growth hormone response to insulin-induced hypoglycaemia was normal.

Radiological examination of the chest revealed that the heart size was at the upper limits of normal. There was a prominent main pulmonary artery segment, the right pulmonary artery was also slightly prominent and there was some suggestion of prominence of the right ventricle. The ascending aorta appeared to be to the right of the midline. In the absence of any abnormalities on clinical examination of the heart, it was felt that these changes were within the range of normal. Radiological examination of the skull revealed 'some suggestion of decrease in size of the sella turcica', no other abnormalities were noted. Examination of the long bones demonstrated advanced skeletal maturation with the epiphyses fused. The bones had the normal adult appearance. 


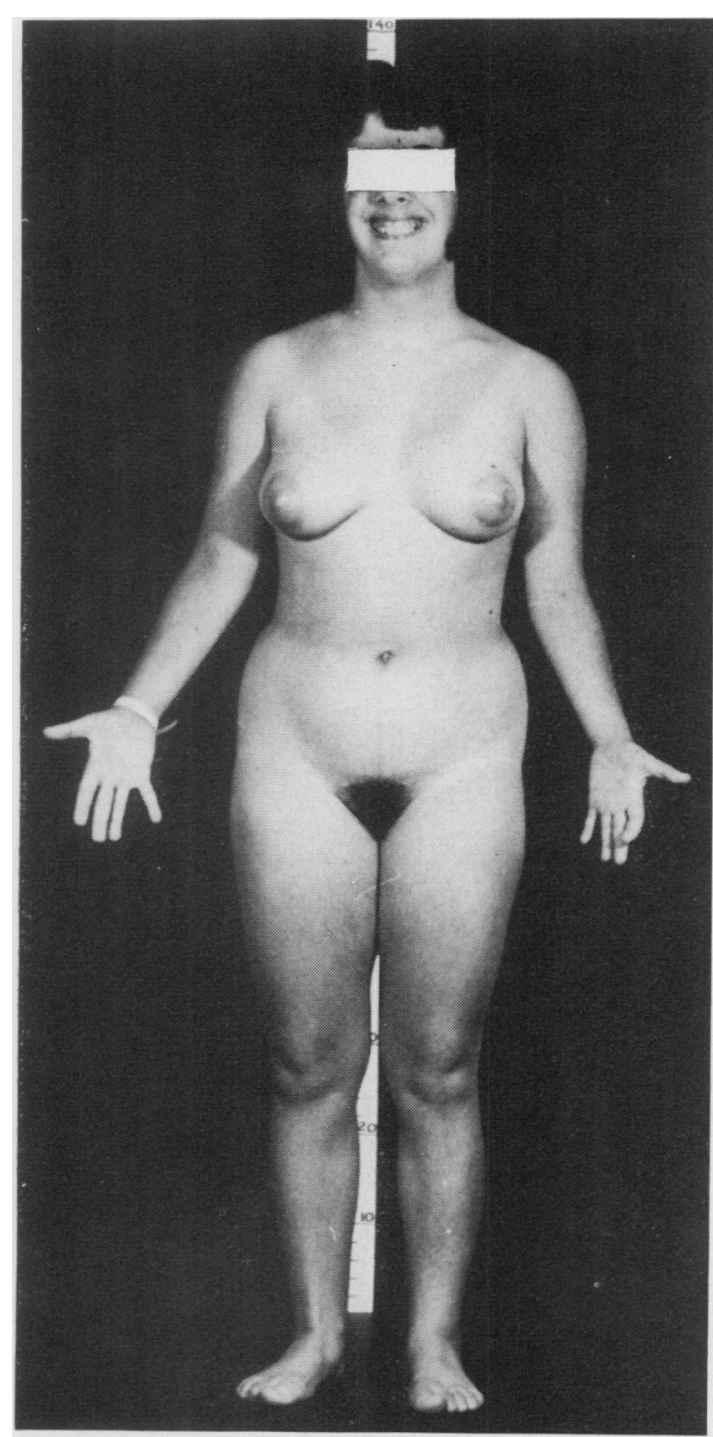

Fig. 1. The patient at age $14 \frac{1}{2}$ years. Note the short stature cubitus valgus, pigmented naevi, and secondary sex characteristics.

Because of the cytogenetic studies described below, it was decided to inspect her internal genitalia through a laparoscope (Figs. 2 and 3). The uterus and both Fallopian tubes appeared normal. The left ovary was normal in size but appeared cystic and according to $\mathrm{Dr}$ Robert Thompson, who performed the study, probably contained a corpus luteum although no yellowish tissue was definitely identified. The right ovary was elongated and had an irregular surface. It appeared quite small in size. A biopsy was taken from each ovary. Both ovaries contained primary oocytes, primitive follicles, and had an increase in the ovarian stroma (Fig. 4). The specimen from the left ovary contained an area of haemorrhage that, on serial section, was believed to be compatible with but not diagnostic of a regressing corpus luteum.

Cytogenetic Studies (Table). Buccal smears were obtained from the left and right cheeks on multiple occasions over a period of three years. A total of 600

TABLE

CYTOGENETIC STUDIES

\begin{tabular}{l|c|c}
\multicolumn{1}{c|}{ Tissue } & No. of Cells & Findings \\
\cline { 2 - 3 } Lymphocytes & 124 & $45, \mathrm{X}$ \\
Skin fibroblasts & 50 & $45, \mathrm{X}$ \\
$\begin{array}{l}\text { Buccal epithelium } \\
\text { Polymorphonuclear }\end{array}$ & 600 & Chromatin negative \\
leucocytes & 500 & Drumsticks negative \\
$\begin{array}{c}\text { Smooth muscle } \\
\text { (blood vessels of } \\
\text { tube and ovary) }\end{array}$ & & Chromatin negative \\
\hline
\end{tabular}

cells were examined; at no time was a sex chromatin body identified. Polymorphonuclear leucocytes were examined for the presence of drumsticks; none were found in 500 cells examined. No sex chromatin bodies were found in the nuclei of the smooth muscle of the blood vessels of the ovarian and Fallopian tube biopsy specimens. Peripheral blood lymphocytes were cultured using standard techniques. One hundred and twentyfour cells were studied on two separate occasions, $122 \mathrm{had}$ 45 chromosomes. Twenty-five metaphase plates were karotyped and in each, a C group chromosome was missing. One cell had 44 chromosomes and two $C$ group chromosomes were missing. One cell had 45 chromosomes plus a small acentric fragment; a $\mathrm{C}$ group chromosome was missing from this cell. Chromosome analysis from fibroblasts from a skin biopsy revealed the karotype to be 45,X; 50 metaphase plates were counted. All had 45 chromosomes, 10 were analysed and in each, a $\mathrm{C}$ group chromosome was missing. The tissue culture of the ovary did not grow.

\section{Discussion}

There are several possible explanations for the normal sexual development, regular menses, and the normal appearance of the ova in our patient.

This phenotype could be explained on the basis of chromosome mosaicism. It is possible that the patient has a $46, \mathrm{XX}$ cell line that we have been unable to demonstrate. While it is impossible by present techniques to be absolutely certain that mosaicism is not present, this is not considered a likely explanation since on repeated examinations, sex chromatin was not found in buccal epithelium, drumsticks were not demonstrated in peripheral blood polymorphonuclear leucocytes, and the lymphocyte and skin fibroblasts karyotypes were 


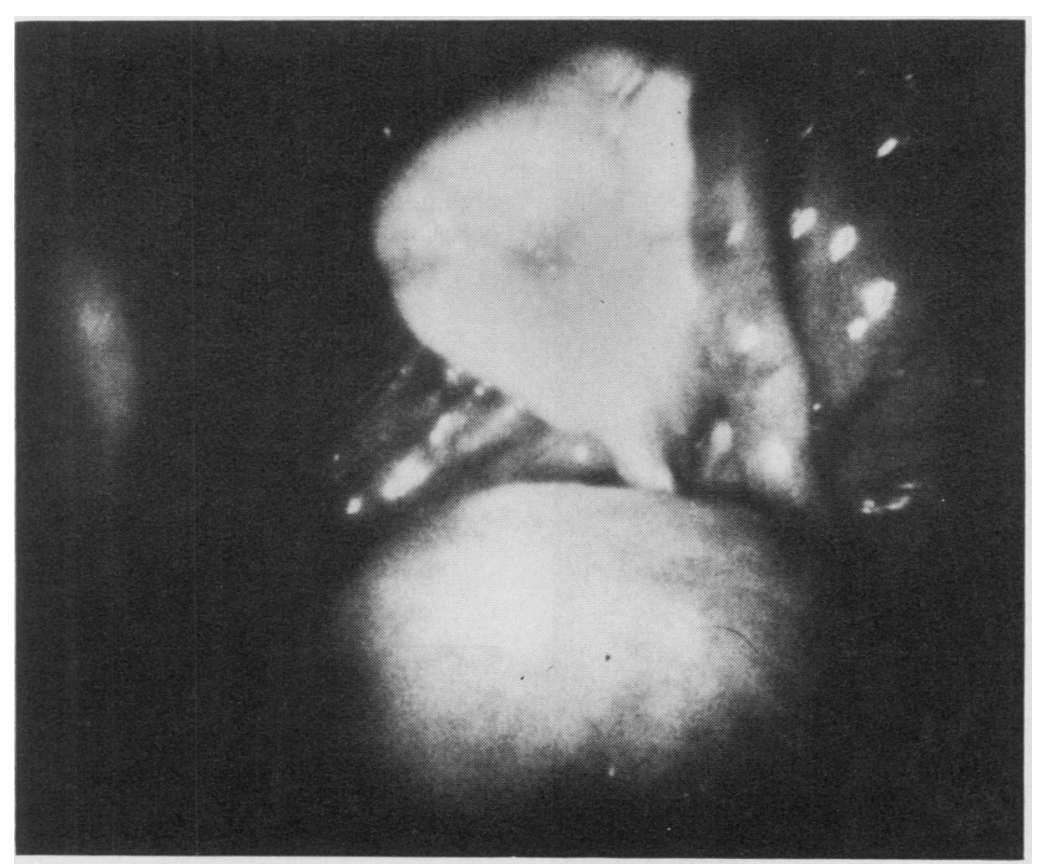

Fig. 2. The internal genitalia of the patient photographed through a laparoscope.

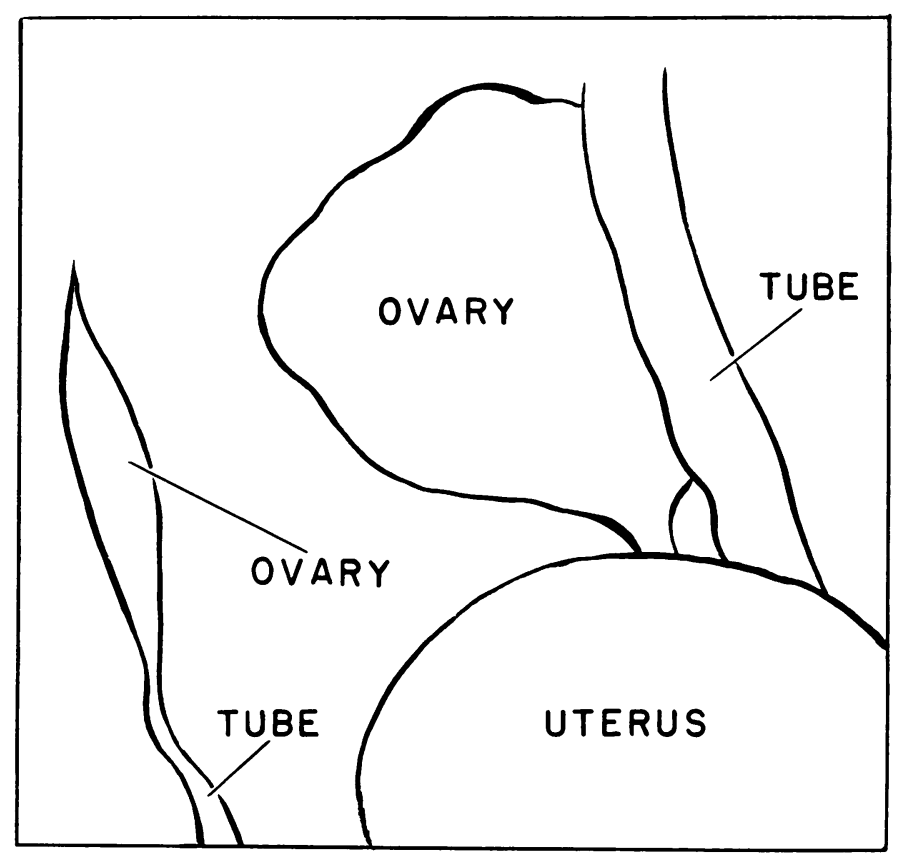

Fig. 3. Diagrammatic representation of Figure 2. 


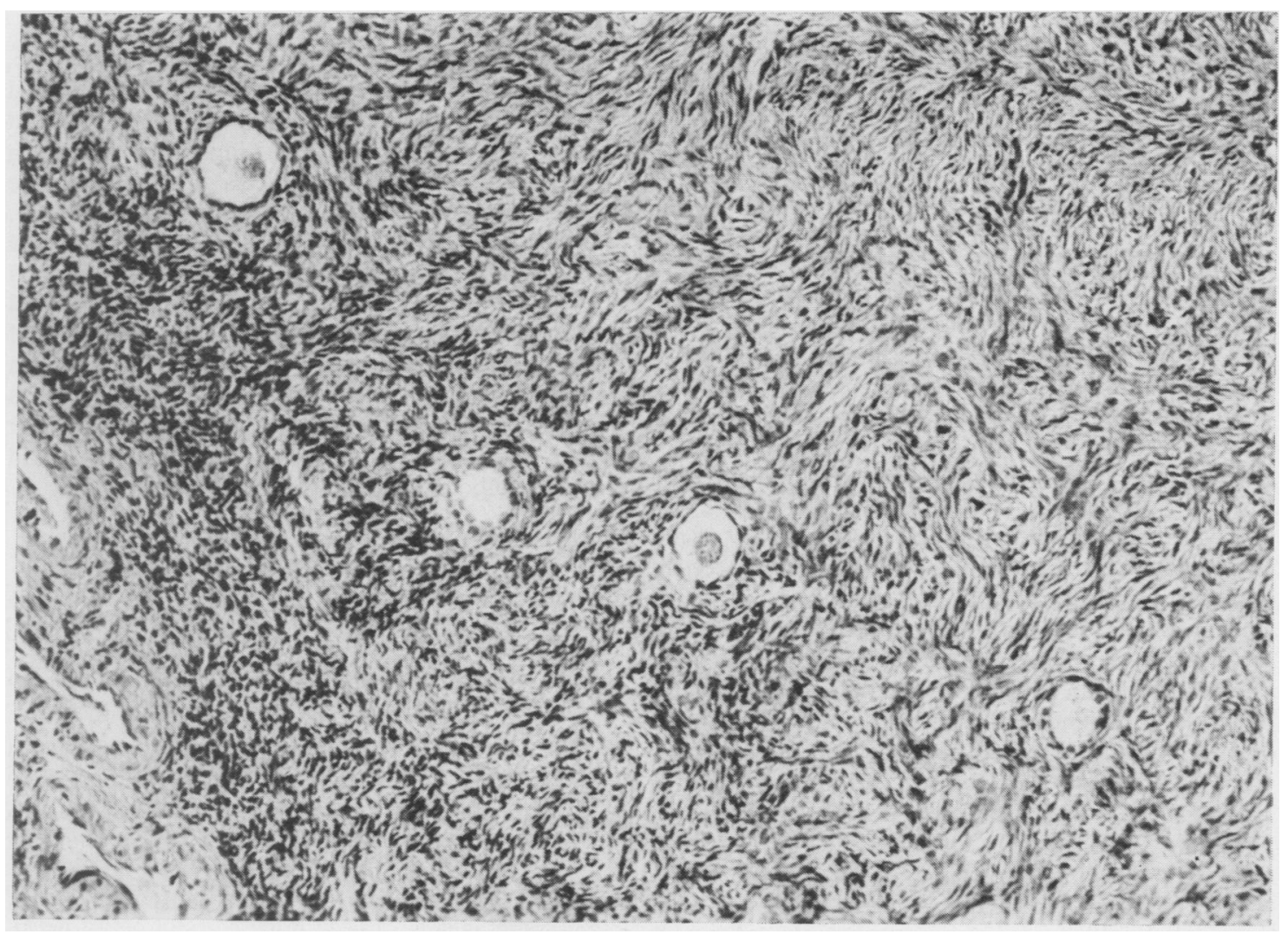

Fig. 4. Section of material from ovarian biopsy demonstrating primordial follicles with ova and abundant ovarian stroma ( $\times 195$ ).

consistently 45,X. Unfortunately, culture of the ovarian tissue was unsuccessful; however, we were unable to demonstrate sex chromatin in the smooth muscle of the blood vessels in the biopsy specimen.

A second possible explanation of the phenotype relates to the presence of two cell lines, $46, \mathrm{XX}$ and $45, X$ at an earlier time in the patient's life with selective disappearance of the $46, \mathrm{XX}$ cell line. While Taylor (1968) has described this type of invivo clonal evolution, Taysi, Kohn, and Mellmen (1970) have observed that most patients who have chromosome mosaicism will continue to demonstrate this mosaicism when retested years later.

The third and most likely explanation is that the ovary in the 45,X patient is anatomically and histologically normal at the early stages of gestation and undergoes atrophy with disappearance of the follicles over periods of time that vary from individual to individual. After the 45,X karyotype was described in patients with Turner's syndrome, it was assumed that two $\mathrm{X}$ chromosomes were necessary for the development of the fetal ovary and that in the absence of a fetal gonad, the Fallopian tubes and uterus developed from the Müllerian ducts in the same way that rabbits, which are castrated in utero, developed Fallopian tubes and a uterus regardless of their chromosomal sex. In 1963, Jones, Ferguson-Smith, and Heller, hypothesized that the ovary did not develop in $45, \mathrm{X}$ patients because of the failure of the primordial germ cells to migrate into the genital ridge. This theory was advanced after studying the histology of the streak gonad in 11 patients with ovarian agenesis and reviewing the available literature describing the microscopic appearance of these gonads. No patient in this study was found to have primary germ cells or follicular apparatus. However, there is now evidence that early in fetal life the gonads of 45, $\mathrm{X}$ individuals are indistinguishable from those of normal females both on gross and microscopic examinations. Singh and Carr (1966) found primordial germ cells and pregranulosa cells in the ovaries of $45, \mathrm{X}$ fetuses up to the third month of intrauterine life. In one specimen, a single primordial follicle was found. They found that with increasing fetal age, there was an increase in the 
connective tissue of these gonads. There is additional evidence demonstrating that fetal ovaries of 45,X individuals have primordial germ cells and that these are lost over a varying period of time. The reports describing the histology of gonads in infants with Turner's syndrome have to be interpreted carefully. Only those cases in which chromosome analysis was performed and the karyotype was found to be $45, \mathrm{X}$ without evidence of mosaicism, should be included. Even if these criteria are followed, there is apparently great variability in the histologic appearance of the ovary in an infant with the 45,X karyotype. Carr, Hagger, and Hart (1968) found both clusters of germ cells without follicles and apparently normal primordial follicles in an 45,X infant. Frøland, Zykke, and Zachau-Christiansen (1963) and Conen and Glass (1963) found primordial follicles in the ovary of an $45, \mathrm{X}$ infant while a second infant reported by Conen and Glass and the two infants examined by Court Brown et al (1964) had the streak ovaries without germ cells or primordial follicles but with the abundant ovarian stroma that is typical of the ovary of the adult patient with gonadal dysgenesis. Hodel and Egli (1965) found no germ cells in the ovary of the $45, \mathrm{X}$ infant they examined. In a recent report, Bove (1970) found germ cells and germinal nests simulating primordial follicles but no normal follicles. The high incidence of infants who have a 45,X karyotype and who also have germ cells and primordial follicles is in contrast to the rarity of these findings in adolescent and adult patients with the same karyotype. Bahner et al (1960) reported a 45,X female who had normal menses until the age of 39 (her age at the time of that report) and who gave birth to a normal male child at 31 years of age. Spontaneous menstruation in patients with $45, \mathrm{X}$ karyotypes has been reported by several investigators (Stewart, 1960; Lindsten, 1963; Monardo, 1965).

The gradual but variable rate of loss of germ cells in patients with Turner's syndrome $(45, X)$ is analogous to the gradual loss of germ cells in patients with Klinefelter's syndrome (XXY). Lanman et al (1960) found no germ cells in a testicular biopsy from a patient with double aneuploidy, Klinefelter's syndrome and Down's syndrome, while FergusonSmith (1959) found that some prepubertal patients with Klinefelter's syndrome had reduced numbers of germ cells and others had no germ cells.

It is probable that as cytogenetic studies are performed in large phenotypically normal populations or as the $45, \mathrm{X}$ infants found in newborn surveys are followed, other examples of variation in the rate of loss of germ cells and follicles in 45, $\mathrm{X}$ individuals will be found.

\section{Summary}

A patient is presented who had a 45,X karyotype, with no evidence of mosaicism, in whom sexual development was normal, and who had normal menstrual periods. Ovarian biopsy revealed both oocytes and primordial follicles and a structure strongly suggestive of a regressing corpus luteum. These findings are interpreted in the light of the histologically normal ovaries in early abortuses with the 45,X karyotype in whom oocytes are found within the ovary and the gradual disappearance of the ova over a variable period of time which can extend for many years. The defect in Turner's syndrome then is not one of absent germ cells but rather one of inability to maintain the ova and primary follicles that are originally present.

\section{REFBRENCES}

Bahner, F., Schwarz, G., Hienz, H. A. and Walter, K. (1960) Turner-Syndrom mit voll ausgebildeten sekundaren Geschlechtsmerkmalen und Fertilitït. Acta Endocrinologica, 35, 397404.

Bove, K. E. (1970). Gonadal dysgenesis in a newborn with XO karyotype. American fournal of Diseases of Children, 120, 363366.

Carr, D. H., Hagger, R. A., and Hart, A. G. (1968). Germ cells in the ovaries of XO females. American fournal of Clinical Pathology, 49, 521-526.

- Conen, P. E., and Glass, I. (1963). 45/XO Turner's syndrome if the newborn: report of two cases. Fournal of Clinical Endocrinoe logy and Metabolism, 23, 1-10.

Court Brown, W. M., Harnden, D. G., Jacobs, P. A., Maclean, Nç and Mantel, D. J. (1964). Abnormalities of the sex chomosome complement in man. Medical Research Council Special Report. Series 305. HMSO, London.

Ferguson-Smith, M. A. (1959). The prepubertal testicular lesion in chromatin-positive Klinefelter's syndrome (primary microorchidism) as seen in mentally handicapped children. Lancet, 1 , 219-222.

Frøland, A., Zykke, A., and Zachau-Christiansen, B. (1963). Ovarian dysgenesis (Turner's syndrome) in the newborn. Acta Pathologica et Microbiologica Scandinavica, 57, 21-30.

Hodel, C., and Egli, F. (1965). Ullrich-Turner-Syndrom beim Neugeborenen mit aortenisthmusstenose und vena cava superior sinistra. Annales Paediatrici, 204, 387-396.

Jones, H. W., Ferguson-Smith, M. A., and Heller, R. H. (1963). The pathology and cytogenetics of gonadal agenesis. American fournal of Obstetrics and Gynecology, 87, 578-600.

Lanman, J. T., Sklarin, B. S., Cooper, H. L., and Hirschhorn, K. (1960). Klinefelter's syndrome in a ten-month-old mongolian idiot. New England fournal of Medicine, 263, 887-890.

Lindsten, J. (1963). The Nature and Origin of X Chromosome Aberrations in Turner's Syndrome: a Cytogenetical and Clinical Study of 57 Patients. Almquist and Wiksells, Uppsala.

Monardo, A. (1965). Gonadal dysgenesis in a woman after seventeen years of regular menses. American fournal of Obstetrics and Gynecology, 91, 106-109.

Singh, R. P., and Carr, D. H. (1966). The anatomy and histology of XO human embryos and fetuses. Anatomical Record, 155, 369375.

Stewart, J. S. S. (1960). Gonadal dysgenesis: the genetic significance of unusual variants. Acta Endocrinologica, 33, 89-102.

Taylor, A. I. (1968). Cell selection in vivo in normal/G trisomic mosaics. Nature, 219, 1028-1030.

Taysi, K., Kohn, G., and Mellman, W. J. (1970). Mosaic mongolism. II. Cytogenetic studies. Fournal of Pediatrics, 76, 880885. 